\title{
REVIEW
}

\section{Using genetics to inform the pharmacological targeting of neuroendocrine neoplasms}

\author{
Ashley K Clift $1,2, *$ and Andrea Frilling1,* \\ 1Department of Surgery and Cancer, Imperial College London, London, UK \\ 2NHS Nightingale Hospital London, London, UK
}

Correspondence should be addressed to A Frilling: a.frilling@imperial.ac.uk

*(A K Clift and A Frilling contributed equally to this work)

\begin{abstract}
Neuroendocrine neoplasms (NEN) are a class of tumours heterogeneous in terms of their anatomical sites of origin and clinical behaviour. Outdated perspectives of indolence have been superseded by appreciation for their myriad clinical challenges, such as the high rates of regional and distant metastases at initial diagnosis, lack of clarity on optimal treatment strategies/sequencing, and incompletely elucidated genetic/other pathophysiological drivers. The first randomised controlled trials in this arena were published approximately a decade ago - since then, increased understanding of the genetic drivers and signalling pathway perturbations in these tumours have suggested promise for precision therapy influenced by an individual tumour's molecular sub-type, but this is yet to be realised for manifold reasons. In this article, the authors review the genetic landscapes as currently understood for selected forms of NEN and discuss the current and developing evidence to support the use of genetic information to influence therapy. They provide a critical assessment of the potential limitations of using such approaches and also posit avenues for future developments in this arena.
\end{abstract}

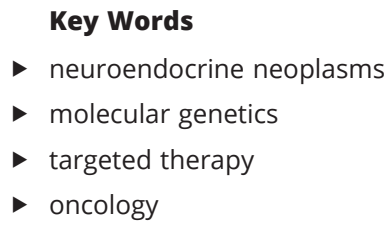

\section{Introduction}

Neuroendocrine neoplasms (NEN) represent a heterogeneous class of tumours that arise from nigh ubiquitously dispersed neuroendocrine cells, which may be stratified into clinically meaningful sub-groups on the basis of their proliferative capacity and degree of differentiation into neuroendocrine tumours (NET) or neuroendocrine carcinoma (NEC) (Rindi et al. 2007). The former is relatively indolent as compared to adenocarcinomas arising from the same organs but display stark rates of lymph node and distant metastasis at initial presentation (Miller et al. 2014, Pavel et al. 2016) and require multimodal strategies for disease control (Clift et al. 2020), whereas the latter pose more standard oncological clinical challenges in terms of rampant disease aggression accorded by high mitotic rate (GarciaCarbonero et al. 2016). Neuroendocrine neoplasms most commonly arise from the gastrointestinal/pancreatic and bronchopulmonary systems (Hauso et al. 2008, Ellis et al. 2010) but notably also from the thyroid and skin (Fraenkel et al. 2015, Becker et al. 2017), may exhibit divergent clinical behaviours chiefly manifested in the range of clinical sequelae (asymptomatic to florid syndromes of hormone hypersecretion) and, in keeping with their diverse cells of origin, diverse pathophysiological underpinnings such as genomic landscape aberrations.

An evolution towards 'precision' therapeutic strategies for multiple cancers has occurred over the past two decades, driven by an ever-deepening elucidation
C) 2020 Society for Endocrinology Published by Bioscientifica Ltd. Printed in Great Britain 
of factors predicating biologically and thus clinically distinct sub-types of individual tumour classes and robust clinical evidence for the superiority of some treatment concepts in particular clinical scenarios. The concept of 'targeted' therapy eschews the blunt approach of promulgating an indiscriminate holocaust of cytotoxicity on any rapidly dividing cells as with traditional chemotherapy. Instead, it migrates towards the targeting of cancer-specific alterations in genetic landscape, protein expression, pathway activity or cell biology. Theoretically, it aims to minimise the 'off-target' adverse effects of pharmacological agents and maximise disease response by tailoring the strategy to the personal molecular biology of a given individual's tumour.

Targeted therapy may comprise tumour-preferential or tumour-specific delivery of pharmaceutical agents dependent on uptake by or binding to tumour cellspecific receptors (Strosberg et al. 2017), selective inhibition of signal transduction pathways in cancerous cells (Raymond et al. 2011, Yao et al. 2011), modification of gene expression, synthetic lethality to engender apoptosis (Clift et al. 2015), inhibition of angiogenesis, immunotherapy (Weber \& Fottner 2018) and also oncolytic viral gene therapy (Leja et al. 2011). Such approaches have been rendered feasible with advances in integrating phenotypic data with those from multiple high-throughput profiling technologies ('omics') (Kinross et al. 2013a, Pavel et al. 2017, Malczewska et al. 2019).

In the early days, genetics was proclaimed as the impending apotheosis of directed cancer treatment and the concept of oncogene addiction (Pagliarini et al. 2015) has been in the oncologic lexicon for some time - namely, the dependence on one or a small number of genes to maintain a malignant phenotype and survival. While a 'silver bullet' has not been identified (nor will it ever be) this cannot detract from tangible, valuable progress in the realm of understanding the genomic landscapes of NEN, nor from the beginnings of pharmacological targeting of tumours based on their genetic profile.

This review provides a brief recapitulation of the genomic landscape of the commonest neuroendocrine neoplasms and/or most relevant to genetically targeted therapy (pancreatic, small bowel, lung and thyroid) before turning to a comprehensive review of the state of clinical evidence regarding precision therapy for these tumours dictated by their genetic profiles. Throughout, there is an emphasis on the advantages and limitations of these approaches. Lastly, this review anticipates future perspectives and outlines strategies for the next advances in this aspect of this clinical arena.

(c) 2020 Society for Endocrinology Published by Bioscientifica Ltd. Printed in Great Britain

\section{The genetic landscape of selected neuroendocrine neoplasms}

\section{Pancreatic neuroendocrine neoplasms}

The presence of MEN1 mutations in pancreatic NEN have been long accepted since earlier sequencing studies demonstrated a rate of approximately 35\% (Marini et al. 2018). Encoding menin, this gene is implicated in cell cycle regulation, suppression of the PI3K/mTOR pathway signalling systems and promotion of homologous DNA repair mechanisms. More recent studies in pancreatic NEN genetics have demonstrated that DAXX or ATRX mutations also occur commonly (up to 43\%) and, interestingly, these two seem mutually exclusive (Jiao et al. 2011). The former is implicated in regulation of apoptosis and distribution of PTEN, whereas the latter functions within chromatin remodelling networks.

A seminal comprehensive study of 98 panNEN by the International Cancer Genome Consortium identified that they are less mutationally active than pancreatic adenocarcinoma (0.82 mutations per megabase DNA vs 2.62, respectively (Waddell et al. 2015)) and may display five forms of mutational signatures, namely: deamination, APOBEC/AID (enzymatic deamination of cytosine residues), BRCA (failure of homologous recombinationmediated double strand break repair), cosmic signature 5 (unknown aetiology) or a novel signature of $\mathrm{G}: \mathrm{C}>\mathrm{T}$ :A transversions (inactivated base excision repair due to biallelic loss of MUTYH) (Scarpa et al. 2017). Chromothripsis may also occur in 9\% of cases (Scarpa et al. 2017).

Pancreatic tumours may also display chromosomal alterations on comparative genome hybridisation. Larger non-functioning pancreatic NETs have more chromosomal aberrations than smaller ones, and metastases of non-functional pancreatic NETs have more alterations than matched primary tumours (Zhao et al. 2001, Marinoni et al. 2014). Furthermore, in insulinomas, metastatic tumours tend to display far greater extents of chromosomal aberrations than non-metastatic tumours, which may have relevance for clinical outcomes (Jonkers et al. 2005). Specific chromosomal losses in metastatic pancreatic NET may include 6q, 3p, 11pq and 22q or gains of 17q, 4p and 41 (Wild et al. 2002, Floridia et al. 2005, Pea et al. 2016).

In the context of a $41 \%$ rate of MEN1 mutation, four core pathogenic pathways have been elucidated (Scarpa et al. 2017):

1) DNA repair deficiencies - mutations in $11 \%$ of patients, genes include MUTYH, CHEK2, BRCA2 
2) Altered chromatin modification - mutations in 10\% of patients, genes include SETD2 and MLL3

3) Alterations in telomere lengths - mutations in 33\% of patients, genes include $D A X X$ and $A T R X$

4) Activation of the mTOR pathway - mutations in $12 \%$ of patients, genes include PTEN, DEPDC5, TSC1 and TSC2

A key clinical debate in PanNEN is the management of small, well-differentiated tumours, specifically on how to identify higher risk tumours that may be suitable for resection or more indolent tumours that could be suitably managed by observation. Two recent studies have begun to illuminate how molecular genetic methods may be able to risk stratify such lesions and impact clinical decision making. One notable recent study undertook immunolabelling of DAXX/ATRX and analysis for alternative lengthening of telomeres (ALT) in 87 small, primary PanNEN ( $<3 \mathrm{~cm}, 32$ metastatic cases), with next generation sequencing in a subset of 48 tumours, half of which metastasised (Pea et al. 2020). Three molecular subtypes were identified on the basis of genetic sequencing: one with recurrent chromosomal gains, DAXX mutations and ALT positivity had a 73\% metastasis rate; another group with limited copy number variations had a $42 \%$ rate of metastasis; and the last was defined by chromosome 11 loss, which was associated with a $35 \%$ rate of metastasis. Another study compared the mutational profiles of PanNEN that were larger than $2 \mathrm{~cm}(n=29)$ or smaller than $2 \mathrm{~cm}(n=27)$. Herein, it was observed that there was a significantly higher mutational burden in tumours $>2 \mathrm{~cm}$, the prevalence of DAXX mutations was borderline significantly higher in larger tumours, and DAXX mutations were associated with increased histological grade, relapse after surgery and reduced disease-free survival (Cives et al. 2019a).

\section{Small intestinal neuroendocrine neoplasms}

In contrast to the relatively well elucidated genomic landscape of pancreatic NEN, the mutational drivers of small intestinal (SI) NEN remain elusive. Indeed, comprehensive sequencing efforts have demonstrated that SINEN are mutationally quiet (average 0.1 mutations per megabases DNA vs 3.96 for small intestinal adenocarcinoma) (Banck et al. 2013, Hänninen et al. 2018), yet this paucity of genome aberrations is partially compensated in the more deeply understood epigenetic landscape.
The only consistently identified mutated gene in SINEN thus far is CDKN1B which encodes a cyclindependent kinase, p27; this occurred in only $10 \%$ of the 50 cases sequenced and $8 \%$ of the 180 further 'extension set' sequenced by Francis et al. (2013). These tend to be frameshift-inducing, loss-of-function mutations. Nevertheless, neither p27 expression nor clinical behaviour has been categorically demonstrated to be different between CDKN1B WT or mutant SINEN (Crona et al. 2015). Additional, albeit, rarer mutational 'hotspots' encountered thus far include APC (7.7\%), CDKN2C (7.7\%) BRAF, KRAS, PIK3CA and TP53 (3.8\% each) (Bottarelli et al. 2013, Simbolo et al. 2018). Somatic copy number variations have been observed in almost $80 \%$ of SINEN, particularly segmental losses of chromosome 18: LAMA3 (encodes laminin), SERPINB5 (a tumour suppressor) and RANK/TNFRRSF11A (TNF receptor family member) indeed demonstrate epigenetic disruption associated with loss of heterozygosity of chromosome 18, whereas allelic loss of BCL2, CDH19, DCC and SMAD4 (all located on chromosome 18) were observed in $44 \%$ of 52 sequenced cases of sporadic SINEN (Wang et al. 2005, Kim et al. 2008, Kulke et al. 2008, Stålberg et al. 2016).

Epigenetic disruption in SINEN is better categorised, with differential promoter methylation of RASSF1A and CTNNB1 seen between primary and metastatic SINEN and increased methylation of TP73, CHFR and RUNX3 seen in SINEN (Verdugo et al. 2014, Karpathakis et al. 2017). There appears to be three molecular sub-types of SINEN on comprehensive copy number variance analysis, each with significantly different DNA methylation profiles impacting VEGF, EGFR and mTOR pathways, as well as progression-free survival (Karpathakis et al. 2016):

Group A: chromosome 18 loss (includes cases with CDKN1B mutations

Group B: No large copy number variations

Group C: multiple chromosomal copy number variations

\section{Bronchopulmonary neuroendocrine neoplasms}

Accounting for approximately 20\% of all NEN that arise, those arising from the bronchopulmonary system comprise four histological classes: typical carcinoid, atypical carcinoid, large-cell neuroendocrine carcinoma and small cell lung carcinoma (SCLC). Several series have examined the genetic landscape of lung NEN, with varying coverage of the aforementioned histological forms. A notable study of multiple forms of lung cancer by the Clinical Lung Cancer Genome Project identified that lung 
carcinoids display a relatively rare degree of mutations and copy number variation, whereas SCLC and largecell tumours frequently harbour mutations in TP53 and inactivation of $R B 1$; there is also copy number variation in FHIT, MYCL1 and MYCN in SCLC (Clinical Lung Cancer Genome Project \& Network Genomic Medicine 2013). Further aberrations detailed include somatic genomic rearrangements of TP73 and inactivated NOTCH-family genes in SCLC (George et al. 2015). In carcinoids, TP53 and $R B 1$ mutations appear rare, but mutations in histone modifiers are frequently observed, especially sub-units of the SWI/SNF complex; MEN1, PSIP1 and ARID1A are commonly mutated (Fernández-Cuesta et al. 2014).

\section{Medullary thyroid carcinomas}

Accounting for up to 5\% of all thyroid cancers, medullary thyroid carcinoma (MTC) arises from calcitonin-producing parafollicular C cells of the thyroid. The archetypal genetic aberrances encountered in MTC are typically gainof-function mutations in the RET proto-oncogene (up to $65 \%$ of patients) (Raue \& Frank-Raue 2009, Romei et al. 2016), but others have been observed in RAS (20-25\% of RET WT cases) (Moura et al. 2015).

Hereditary MTC (20-25\% of tumours) appears as part of multiple endocrine neoplasia syndrome type 2 (MEN2), which can be sub-classified into MEN2A or MEN2B (Ceolin et al. 2019). The disease progression of MTC in MEN2A is associated with the RET codon in which the causal mutation exists - the vast majority affect the cysteine-rich extracellular domain, although amino acid changes in codons 768, 790, 791, 804, 844 and 891 have been seen and mutations in non-cysteine codons appear to lower aggressiveness (Machens et al. 2003, Ceolin et al. 2019, Maciel et al. 2019).

\section{Clinical evidence and results for gene-targeted therapy in NEN}

While targeted therapy is indeed becoming progressively more realised as a concept (Table 1), such as the use of tyrosine kinase inhibitors predicated by common constituent over-activation of specific cell signalling pathways driven by multiple possible mutations, no final results from a trial have yet been reported showing the specific targeting of individual tumour-specific genetic profiles in NEN.

\section{Pharmacological agents for targeted therapy in NEN}

Sunitinib is an inhibitor of multiple tyrosine kinases, including all forms of VEGFR and therefore exerts

Table 1 Targeted therapies that may be utilized in the medical treatment of neuroendocrine neoplasms.

\begin{tabular}{|c|c|}
\hline Pharmacological agent & $\begin{array}{l}\text { Molecular mechanism } \\
\text { and targets }\end{array}$ \\
\hline Sunitinib & $\begin{array}{l}\text { Multi-kinase inhibitor } \\
\text { PDGFRs, VEGFRs, CD117 (c-KIT) } \\
\text { Also binds to RET, CD114, } \\
\text { CD135 }\end{array}$ \\
\hline Everolimus & $\begin{array}{l}\text { Tyrosine kinase inhibitor } \\
\text { mTOR (esp. mTORC1 complex) }\end{array}$ \\
\hline
\end{tabular}

Cabozatinib

Vandetanib

Bevacizumab

Multi-kinase inhibitor Targets: MET, RET, VEGFR2, AXL, FLT3, c-KIT

Multi-kinase inhibitor Targets: VEGFR2, EGFR and RET

\section{Approved indications}

Unresectable, metastatic,

progressive pancreatic NEN

Advanced, progressive, welldifferentiated, non-functional pulmonary or gastrointestinal NEN

Medullary thyroid carcinoma

Angiogenesis inhibitor -
humanised monoclonal
antibody
Target: vascular endothelial
growth factor (VEGF-A)

Medullary thyroid carcinoma

Poorly differentiated neuroendocrine carcinomas (Sometimes with FOLFIRI, FOLFOX or FOLFIRINOX)

\section{Clinical targeting strategy/rationale}

Not routinely used to target specific mutations

Targets frequently perturbed pathways

Not routinely used to target specific mutations

Targets frequently perturbed pathways

Not routinely used to target specific mutations

Targets frequently perturbed pathways

Not routinely used to target specific mutations

Targets frequently perturbed pathways

Not used to target specific mutations

Treatment strategy adapted from other tumours (adenocarcinomas)

AXL is also known as UFO, ARK or JTK11; c-KIT, tyrosine-protein kinase KIT (or CD117); FLT3, FMS-like tyrosine kinase 3 (or CD135); mTOR, mammalian target of rapamycin; NEN, neuroendocrine neoplasms; PDGFRs, platelet-derived growth factor receptors; RET, 'rearranged during transfection' tyrosine kinase; VEGF, vascular endothelial growth factor, VEGFRs, vascular endothelial growth factor receptors.

c) 2020 Society for Endocrinology Published by Bioscientifica Ltd. Printed in Great Britain 
somewhat of a targeted effect on angiogenesis. It was approved by the FDA for the treatment of unresectable, metastatic, progressive pancreatic neuroendocrine neoplasms following the publication of phase III RCT results demonstrating significant prolongation of progression-free survival over the use of placebo (median PFS 11.4 months vs 5.5 months) (Raymond et al. 2011).

Everolimus is an inhibitor of mammalian target of rapamycin (mTOR), a serine-threonine kinase whose eponymous pathway is implicated in regulation of cell proliferation, apoptosis and angiogenesis. It was approved by the FDA following the publication of RADIANT-3: herein, patients with advanced low- or intermediate-grade pancreatic NET with progression in the last 12 months. Median PFS with everolimus was 11 months vs 4.6 months with placebo. (Yao et al. 2011). Following RADIANT-3, a phase III study of everolimus was undertaken in advanced, progressive, well-differentiated, non-functional pulmonary or gastrointestinal NET - again, prolonged PFS was demonstrated (11 months vs 3.9 months with placebo) (Yao et al. 2016).

Cabozatinib (Elisei et al. 2013, Schlumberger et al. 2017) and vandetanib (Wells et al. 2010) are two other multikinase inhibitors (MKI), licensed for the therapy of advanced MTC. The former is a c-MET, VEGFR2 and RET MKI that was demonstrated to significantly prolong PFS in patients with progressive MTC (11.2 months vs 4.0 months with placebo) (Elisei et al. 2013). Vandetanib is an MKI for RET, VEGF and EGF receptors and was demonstrated in the trial setting to also significantly prolong PFS in metastatic MTC (30.2 months vs 19.2 months with placebo) (Wells et al. 2012).

However, despite these targeted therapies being implemented in the advanced tumour stage depending on aberrant pathways in their target tumours, these are not strictly 'gene targeted' - the effects of several mutations certainly converge clinically in disruption of these targeted pathways, but their prescription tends to not be (in standard clinical practice) based on the presence of specific mutations on gene sequencing of tumour material.

\section{Ongoing clinical trials of gene-targeted therapy in NEN}

The concept of directing therapy with everolimus or sunitinib (both kinase inhibitors) depending on mutational profiles is currently being assessed in patients with advanced, low-to-intermediate grade NEN of the gastrointestinal tract and pancreas as part of a phase II randomised controlled trial (NCT: 02315625)
(Neychev et al. 2015). Herein, tumour genotype (obtained from biopsy) or germline mutation status (i.e. MEN1 or VHL) will be used to select patients for commencement of either everolimus or sunitinib. Presence of NF1, PTEN, PI3K, AKT, mTOR, VHL, or TP53 mutations will trigger commencement of everolimus due to its targeting of the mTOR pathway in which the pathophysiology of the previously mentioned mutations converge. Those with MEN1, FLT3, PDGFR, or KIT mutations, or those with $>1$ mutation or mutations not known to be actionable with everolimus will start on sunitinib. In the eventuality of disease progression, participants will be transferred to start receiving the other study drug. Long-acting somatostatin analogues also will be administered if patient symptomatology (of hormone secretion) clinically warrants it. With a primary endpoint of progression-free survival, results from this trial are awaited.

Although not specifically targeting a gene mutation or using novel drugs developed to target a specific cellular pathway, the recently commenced MGMT-NET phase II trial (NCT: 03217097) seeks to use O6-methylguanine DNA methyltransferase (MGMT) status as a factor by which to randomise patients with well differentiated advanced duodenopancreatic, pulmonary or unknown primary NETs either to alkylating agent chemotherapy or oxaliplatinbased chemotherapy (Lemelin et al. 2019). Alkylating agents induce alkylation or methylation of DNA bases, forming as N7-methylguanine and N3-methylguanine (both addressed by base excision repair mechanisms) but also 06-methylguanine, which may be repaired directly by MGMT but, if unsuccessful, this latter species may trigger futile cycles of mismatch repair with ensuing apoptosis (Zhang et al. 2011). Specifically, this trial will utilise methylation of the MGMT promoter region as the target of interest, based on previous evidence that such epigenetic modifications influence the efficacy of alkylating chemotherapy in not only NEN but also other tumour types such as glioblastoma. Patients with non-methylated MGMT will be randomised 1:1 to either alkylating therapy or oxaliplatn-based chemotherapy; those with methylated MGMT will be randomised 2:1 to alkylation chemotherapy or oxaliplatin-based chemotherapy.

\section{Immunotherapy}

The principal premise of immunotherapy in neoplastic disease is rooted in reversing the cancer cell subversion and (c) 2020 Society for Endocrinology Published by Bioscientifica Ltd. Printed in Great Britain 
evasion of immune mechanisms, but the best predictors of response to immunotherapy may not be expression of immune proteins (Shen \& Zhao 2018).

Immune escape, wherein aberrant cells avoid identification and eradication, is one fundamental aspect of tumourigenesis with increasingly interesting clinical impact. Much focus has been on the targeting of programmed cell death protein ligand 1 (PD-L1) on tumour cells and its cognate receptor, programmed cell death (PD-1) on $\mathrm{T}$ cells - such interaction abrogates immune activation and reduces the proliferation of $\mathrm{T}$ cells as well as pro-inflammatory cytokines (Webb et al. 2018). Oncological immunotherapy, also referred to as immune checkpoint inhibition, typically seeks to utilise monoclonal antibodies to antagonise either of the two molecular players, with major successes seen with agents such as pembrolizumab (Schachter et al. 2017, Mok et al. 2019), nivolumab (Overman et al. 2018) or avelumab (Motzer et al. 2019) across a range of solid malignancies.

Several clinical trials are ongoing in the field of NEN with regards to immunotherapy and therefore a clear role is yet to be established (Weber \& Fottner 2018), which is tantalising given that, in NEN, there is conflicting evidence regarding the prognostic power of PD-1/PD-L1 (Kim et al. 2016), that data thus far suggest a relatively 'cold' tumour immune micro-environment (Takahashi et al. 2018, Cives et al. 2019b), but that a recent metaanalysis demonstrates that efficacy of immunotherapy in multiple cancers can be observed regardless of PD-L1 positivity/negativity (Shen \& Zhao 2018). PD-L1 status is a sub-optimal biomarker for therapy response, whereas the presence of microsatellite instability - the predilection to genetic hypermutabilty due to defective mismatch repair, manifesting as high mutation rates in short, repeating stretches of DNA - appears to be stronger and is a phenomenon observed in neuroendocrine carcinomas of the stomach duodenum and colon, but rarely in gastrointestinal or pancreatic NET (Sahnane et al. 2015). It is posited that increased mutational burden may favour tumour cell 'antigenicity', but trial evidence is awaited regarding the efficacy of immunotherapy in NEN with sub-analyses regarding the role of MSI on efficacy that may allow 'targeting' of this genetic phenomenon, albeit indirectly.

\section{Limitations of the gene-targeted approach}

Precision or targeted therapy in NEN based on 'druggable' genetic targets is limited at present by several factors:

C) 2020 Society for Endocrinology Published by Bioscientifica Ltd. Printed in Great Britain
1. The genetic landscapes of some tumour types are not fertile ground for pharmacological targeting

As aforementioned, some forms of NEN - especially small intestinal NEN - are mutationally 'quiet', which limits widespread deployment of gene-targeted therapy. Furthermore, the presence of an apparent 'driver' mutation does not always render it druggable or actionable. This has been the case for KRAS and MYC oncogenes for many years, although recent preclinical work suggests that novel agents may be able to antagonise the former (Janes et al. 2018, Bery et al. 2019), a commonly encountered mutation in many solid cancers. The genomic landscape of small intestinal NENs is more remarkable for complex chromosomal alterations which may not offer obvious targets for existing therapies, and the epigenetic profiles of this tumour type are more summarily understood. This suggests that single-gene targeting may not be plausible for the majority of patients.

2. Incomplete characterisation of therapeutic value of targeting some mutations

While wholly commendable endeavours such as the Cancer Genome Atlas or other tumour genetic studies are illuminating the genetic landscape of myriad malignancies, not all identified mutations are known to have relevance for treatment. For example, in one very large molecular phenotypic study of over 5000 patients at Dana Farber Cancer Institute and Brigham and Women's Hospital, 2890 mutations were identified (commonest was KRAS), but only $26 \%$ of mutations directly affected clinical practice and/or predicted resistance to currently available pharmacological agents (Macconaill et al. 2014). Therefore, the field at large has copious work ahead to systematically validate and interrogate the clinical impact of understanding these mutational landscapes.

3. The emergence of drug resistance

Manifold pathophysiological processes converge under Darwinian evolutionary principles to drive development of a neoplastic phenotype. Herein, evolutionary selected-for processes that have enabled multi-cellular life to thrive are progressively disrupted. With the malignant dismantling of a co-operative, co-existing cellular existence, an anarchic state ensues where cells compete for resources and individual survival. Genetic instability begets further genetic variability and the total genetic variation in a single patient's tumour represents a collective of different sub-clones, even if a major 'driver' is commonly seen. 
Plasticity is a concept referring to the ability of cancer cells to transform to other phenotypic states in which they no longer depend on the cellular pathways targeted by oncological agents (Boumahdi $\&$ de Sauvage 2020). In a system where competition between related sub-clones of neoplastic cells occurs, selective targeting of one genetically/phenotypically defined sub-clone can alter the dynamics within the tumour niche so that cells with a pre-existing resistance to the drug become emergent after sensitive sub-clones are eradicated (repopulating the niche) or provide yet another evolutionary pressure that selects for new aberrances that may arise from subsequent mitoses (Gatenby et al. 2019). Either can result in tumours becoming refractory to treatment and drive relapse.

Sensitivity to targeted drugs is therefore a multifactorial issue incorporating genetic diversity which is conceptually ignored by the single-gene target mindset. It also includes phenotypic 'switches' driven by genetic and epigenetic factors, dynamism within the tumour system and overarching evolutionary biology concepts. As such, resistance to gene-targeted therapy should always be anticipated and is almost invariably seen in multiple other solid cancers (Pagliarini et al. 2015, Harrison \& Huang 2018).

4. The presence of targetable mutations are not always powerful predictors of tumour sensitivity to targeted agents

In other tumour types, BRAF, ERBB2, EGFR and $A L K 1$ are good markers of sensitivity, but this is not replicated in myriad other genes from the analysis of cell line studies (Basu et al. 2013). Resistance to therapy is a multifactoral, dynamic and polygenic phenotype that may encompass far more than the presence of a given mutation in the nuclei of cell populations (Boumahdi \& de Sauvage 2020). This is useful context as we progress our understanding of how we can utilise genetic information to better target and treat NEN.

\section{Conclusions and future perspectives: multimodal precision medicine, not just gene-targeted medicine}

Research into the genetic and wider pathophysiological drivers of neuroendocrine neoplasms genesis and clinical behaviour has until recently been frustrated due to relative disease rarity and fragmented approaches (Mafficini \& Scarpa 2018). Through the past decade, multi-centric collaboration has enabled major undertakings: the first randomised clinical trials of medical therapies have been performed (Raymond et al. 2011, Yao et al. 2011, Caplin et al. 2014, Strosberg et al. 2017), albeit only in the noncurative setting, and robust multi-omic interrogation of NEN has also begun to explain the drivers of their divergent behaviours even within tumours that appear histologically similar (Kinross et al. 2013b, Oberg et al. 2016, Modlin et al. 2018). Frustratingly, in keeping with the theme of clinical challenge, adapting and developing the concept of targeted therapy in NEN is yet to truly extend beyond targeting neuroendocrine cell surface receptors or a small number of relatively commonly perturbed signalling pathways. In the latter, it is noteworthy that such agents (everolimus and sunitinib) are usually implemented after disease progression with other agents in the setting of advanced disease, such were the design of the trials that predicated their approval, and are not prescribed on the basis of genetic sequencing individual patients.

Seminal recent papers have demonstrated the possibility of using genetics to inform the pharmacological targeting of some NEN by elucidating the classes and rates of mutations encountered in pancreatic and small intestinal NEN, but there is more work to do to fully realise the concept proven by such work. In NEN, genebased pharmacological targeting rooted in oncogene addiction is certainly possible but will be limited by the extent of existence of identifiable, actionable mutations in some tumour types, as well as the archetypal concepts exemplified in other cancers, namely tumour cell plasticity and the emergence of tumour resistance.

The single mutation targeting concept in NEN (and in many solid cancers), while theoretically a potentially powerful approach, is over-reductionist, at vertiginous risk of eventual failure due to the Darwinian and inherently plastic nature of tumour biology, and will not be sufficient alone to drive the optimal benefits for all patients with NEN. Instead, genetic targeting could be embedded within a more comprehensive concept of precision oncology incorporating mathematical and evolutionary principles (Staňková et al. 2019, West et al. 2020), wherein targeting individual tumours mechanistic dependencies may yield gains in addition to only targeting a single driver mutation. 'Master regulator proteins' are those which in concerted activity within so-called tumour checkpoints are a sine qua non for establishment and maintenance of the neoplastic state. Various lines of evidence from multiple malignancies have demonstrated that subversion of these checkpoints either due to genetic or pharmacological factors abrogates tumour cell viability via checkpoint collapse 
(Carro et al. 2010, Mitrofanova et al. 2015). Master regulator proteins encompass both 'essential' and 'synthetic lethal' proteins, exert significant control over the transcriptional landscape of tumour cells and transcriptional stability, represent non-oncogene drug targets and may be elucidated via different bioinformatic technologies, such as Master Regulator Inference Algorithms (MARINa) or VIPER (Virtual Proteomics by Enriched Regulation analysis) (Carro et al. 2010, Lefebvre et al. 2010, Alvarez et al. 2016).

A comprehensive master regulator analysis was recently undertaken in a cohort of 212 cases of gastrointestinal and pancreatic NEN (small intestinal, pancreatic and rectal) (Alvarez et al. 2018). This study performed RNA sequencing of the sample cohort to obtain gene expression profiling data to derive tumourspecific regulatory models: over 517,000 transcriptional interactions were observed between 5631 proteins and 20,136 target genes. In subsequent unsupervised analyses (i.e. analysis for clustering or patterns in data that are not labelled to identify relatedness without bias), five molecularly distinct sub-types were ultimately observed, with candidate master regulator proteins validated with shRNA silencing: these included early neuroendocrine lineage factors (IKZF1, IKZF3, SPI-I, GFI-I, POUF2), epithelial-to-mesenchymal transition drivers (Notch2, EOMES and GATA3), and immunomodulatory factors (CD45, IL2RB1, CD53, CD86, RUNX3, CIITA and IL10). A library of over 500 pharmacological compounds was compiled for testing in patient-derived NEN cell lines to assess activity and drug effects on expression of identified proteins of interest. The in vitro models were followed by validation of top compounds of interest in murine xenograft models: etinostat (a benzamide histone de-acetylase inhibitor which had the strongest tumour checkpoint collapse effect in the largest number of tumour samples), tivatinib (a c-Met tyrosine kinase inhibitor) and PDX101/belinostat (a pan histone-deacetylase inhibitor). Overall, it was observed that etinostat would be predicted to propagate tumour checkpoint collapse in vivo of $42 \%$ of metastatic GEP-NEN patients (Alvarez et al. 2018). Overall, this key study demonstrates that systematic prioritisation of drugs targeting master regulatory proteins to subjugate their concerted activity in tumour checkpoint biology in individual patients' tumours is feasible and that this may be a wholly appropriate approach to complement and extend oncogene addiction approaches.

In order to make continued, effective progress in this arena with tangible benefits for patients with neuroendocrine tumours, we posit the following avenues for future efforts:

\section{Increased utilisation of 'basket' clinical trials}

Especially in the case of rarer malignancies and given that neoplasms arising from different organs may share common molecular underpinnnings, the use of basket studies where cohorts are assembled on the basis of drug target rather than histopathology/ anatomical derivation are an attractive bypass to efficiently and robustly assess novel molecularly targeted agents. Recent examples include trials for larotrectinib, which targets NTRK-fusion cancers from myriad organs (Drilon et al. 2018). Neuroendocrine neoplasms have only had their first randomised controlled trials published within the last decade with issues of slower recruitment given the relative rarity of the disease if a gene-specific drug trial was designed, basket trials would enable NEN patients to contribute to the rigorous assessment of compounds that may have pan-tumour class efficacy. In instances where trials are undertaken specifically in NEN, then we suggest that the trials be adequately powered for the execution of pre-defined, post-hoc analyses stratifying for molecular genetic sub-types.

2. Deeper understanding of the mechanisms of resistance to targeted therapies to overcome resistance and extend oncogene addiction

In order to understand the ways in which neoplasms can mitigate the effects of targeted therapy, the field must seek to better understand hitherto abstruse aspects of tumour biology, such as the tumour microenvironment, tumour cell plasticity (genetic and nongenetic), and activation triggers for complementary bypass pathways. Better understanding of how tumours trump genetically targeted treatments will illuminate ways to develop novel approaches to sabotage these mechanisms. These could theoretically include therapy with more than one kinase inhibitor, rotation of treatments to 'control' sub-clone expansion or evolutionary dynamics, or other forms of polytherapy (West et al. 2020).

3. Incorporate genetics as part of a multi-omics perspective with which to drive multimodal therapy

As aforementioned, novel approaches that seek to widen the paradigm from purely focusing on oncogene addiction to incorporating analysis of master regulatory proteins have shown major promise in the identification of novel drug targets. Multimodal therapy for neuroendocrine tumours is increasingly utilised,
(C) 2020 Society for Endocrinology Published by Bioscientifica Ltd. Printed in Great Britain 
especially in the setting of liver metastases; however, these decisions are based on oncological factors (tumour behaviour) and technical factors (resectability and anatomical distribution of disease) (Frilling \& Clift 2015). Incorporating genetic and pathway biology information into the treatment strategy opens avenues for a future wherein anti-hormonal therapies can be administered alongside agents that target mechanistic dependence of tumours, with or without agents that target oncogene addiction.

4 Development and validation of novel technologies to longitudinally assess tumour dynamics relevant to targeted therapies

With active anticipation of targeted therapy resistance emergence, advances in radiological assessment and 'liquid biopsy' (Bodei et al. 2016, Khan et al. 2016) may foster new approaches to monitor for early signs of not only the dichotomous outcomes of tumour relapse, but quantitative closeto-real-time changes in tumour sub-clone genetics, metabolic phenotypes or other plastic effects. In the realm of image analysis, radiomics and convolutional neural networks have both been utilised to predict with favourable degrees of accuracy the presence of targetable mutations on CT imaging (Xiong et al. 2018, Jia et al. 2019) and also grade in pancreatic NEN using CT imaging (Luo et al. 2020), suggesting that they could function not only as part of diagnostic solutions (direct targeted genetic sequencing) but also as follow-up (reduction of likelihood of mutation presence, or emergence of another) - this will require an expanded cross-institutional collaboration to develop such models. Circulating tumour cells or transcripts may also be aspects of real-time monitoring for waxing/ waning therapy efficacy. While the former have some issues in NEN, such as the low sensitivity, the latter have been shown to indicate relapse months prior to it being evident on routine imaging. Adaptation of such an approach to the explicit follow-up of patients on targeted therapy will be a tantalising endeavour.

Reinforcement learning is a goal-oriented paradigm in machine learning focussed on sequential decisionmaking tasks: using data inputs, 'software agents' are trained to select the optimal action to be performed at different time points to maximise reward. Such approaches have been shown to select optimal treatments for septic shock (Komorowski et al. 2018) and may represent a wholly novel approach to optimal targeted treatment sequencing in NEN as well as other cancers. Ideally, such models would be provided with data from the longitudinal follow-up of patients being treated with targeted therapies with regular, robust tumour assessments as aforementioned.

In conclusion, directing pharmacological therapy in neuroendocrine neoplasms on the basis of their genetic constitution is theoretically possible due to recent advances in tumour genetic sequencing studies, albeit likelier to be realised in some tumour sub-types rather than others. Thus far, targeted therapy in advanced NEN has focussed on pathways into which a congregation of genetic mutations may impart influence, rather than single target mutations themselves as is seen in solid or haematological malignancies. Accepting the omnipresent risk of treatment relapse with targeted therapy, this avenue is worthy of exploration within the context of multimodal therapeutic strategies for disease control. Concerted efforts in the elucidation of genetic targets, the ascertainment of the appurtenances of pathways relevant to resistance, as well as embedding this alongside a multi-omics approach within a wider precision medicine framework is an exciting new frontier in the personalised treatment of this clinically challenging set of cancers.

\section{Declaration of interest}

The authors declare that there is no conflict of interest that could be perceived as prejudicing the impartiality of this review.

\section{Funding}

This work did not receive any specific grant from any funding agency in the public, commercial, or not-for-profit sector.

\section{Author contribution statement}

Both authors contributed equally to the writing and revision of this manuscript.

\section{Acknowledgements}

This paper was initially presented as a lecture at SfE BES 2019.

\section{References}

Alvarez MJ, Shen Y, Giorgi FM, Lachmann A, Ding BB, Hilda Ye BH \& Califano A 2016 Functional characterization of somatic mutations in cancer using network-based inference of protein activity. Nature Genetics 48 838-847. (https://doi.org/10.1038/ng.3593)

Alvarez MJ, Subramaniam PS, Tang LH, Grunn A, Aburi M, Rieckhof G, Komissarova EV, Hagan EA, Bodei L, Clemons PA, et al. 2018 A precision oncology approach to the pharmacological targeting of mechanistic dependencies in neuroendocrine tumors. Nature Genetics 50 979-989. (https://doi.org/10.1038/s41588-018-0138-4) 
Banck MS, Kanwar R, Kulkarni AA, Boora GK, Metge F, Kipp BR, Zhang L, Thorland EC, Minn KT, Tentu R, et al. 2013 The genomic landscape of small intestine neuroendocrine tumors. Journal of Clinical Investigation 123 2502-2508. (https://doi.org/10.1172/ JCI67963)

Basu A, Bodycombe NE, Cheah JH, Price EV, Liu K, Schaefer GI, Ebright RY, Stewart ML, Ito D, Wang S, et al. 2013 An interactive resource to identify cancer genetic and lineage dependencies targeted by small molecules. Cell 154 1151-1161. (https://doi.org/10.1016/j. cell.2013.08.003)

Becker JC, Stang A, Decaprio JA, Cerroni L, Lebbé C, Veness M \& Nghiem P 2017 Merkel cell carcinoma. Nature Reviews: Disease Primers 3 17077. (https://doi.org/10.1038/nrdp.2017.77)

Bery N, Legg S, Debreczeni J, Breed J, Embrey K, Stubbs C, KolasinskaZwierz P, Barrett N, Marwood R, Watson J, et al. 2019 KRAS-specific inhibition using a DARPin binding to a site in the allosteric lobe. Nature Communications 10 2607. (https://doi.org/10.1038/s41467019-10419-2)

Bodei L, Kidd M, Modlin IM, Severi S, Drozdov I, Nicolini S, Kwekkeboom DJ, Krenning EP, Baum RP \& Paganelli G 2016 Measurement of circulating transcripts and gene cluster analysis predicts and defines therapeutic efficacy of peptide receptor radionuclide therapy (PRRT) in neuroendocrine tumors. European Journal of Nuclear Medicine and Molecular Imaging 43 839-851. (https://doi.org/10.1007/s00259-015-3250-z)

Bottarelli L, Azzoni C, Pizzi S, D’Adda T, Silini EM, Bordi C \& Rindi G 2013 Adenomatous polyposis coli gene involvement in ileal enterochromaffin cell neuroendocrine neoplasms. Human Pathology 44 2736-2742. (https://doi.org/10.1016/j.humpath.2013.06.019)

Boumahdi S \& de Sauvage FJ 2020 The great escape: tumour cell plasticity in resistance to targeted therapy. Nature Reviews: Drug Discovery 19 39-56. (https://doi.org/10.1038/s41573-019-0044-1)

Caplin ME, Pavel M, Ćwikła JB, Phan AT, Raderer M, Sedláčková E, Cadiot G, Wolin EM, Capdevila J, Wall L, et al. 2014 Lanreotide in metastatic enteropancreatic neuroendocrine tumors. New England Journal of Medicine 371 224-233. (https://doi.org/10.1056/ NEJMoa1316158)

Carro MS, Lim WK, Alvarez MJ, Bollo RJ, Zhao X, Snyder EY, Sulman EP, Anne SL, Doetsch F, Colman H, et al. 2010 The transcriptional network for mesenchymal transformation of brain tumours. Nature 463 318-325. (https://doi.org/10.1038/ nature08712)

Ceolin L, Da Silveira Duval MADS, Benini AF, Ferreira CV \& Maia AL 2019 Medullary thyroid carcinoma beyond surgery: advances, challenges, and perspectives. Endocrine-Related Cancer 26 R499-R518. (https://doi.org/10.1530/ERC-18-0574)

Cives M, Partelli S, Palmirotta R, Lovero D, Mandriani B, Quaresmini D, Pelle' E, Andreasi V, Castelli P, Strosberg J, et al. 2019a DAXX mutations as potential genomic markers of malignant evolution in small nonfunctioning pancreatic neuroendocrine tumors. Scientific Reports 918614.

Cives M, Strosberg J, Al Diffalha S \& Coppola D 2019b Analysis of the immune landscape of small bowel neuroendocrine tumors. Endocrine-Related Cancer 26 119-130. (https://doi.org/10.1530/ERC18-0189)

Clift AK, Coupe N \& Middleton MR 2015 Clinical trials of PARP inhibitors with chemotherapy. Cancer Drug Discovery and Development 511-531. (https://doi.org/10.1007/978-3-319-14151-0_22)

Clift AK, Kidd M, Bodei L, Toumpanakis C, Baum RP, Oberg K, Modlin IM \& Frilling A 2020 Neuroendocrine neoplasms of the small bowel and pancreas. Neuroendocrinology 110 444-476. (https:// doi.org/10.1159/000503721)

Clinical Lung Cancer Genome Project (CLCGP) \& Network Genomic Medicine (NGM) 2013 A genomics-based classification of human lung tumors. Science Translational Medicine 5 209ra153. (https://doi. org/10.1126/scitranslmed.3006802)
Crona J, Gustavsson T, Norlén O, Edfeldt K, Åkerström T, Westin G, Hellman P, Björklund P \& Stålberg P 2015 Somatic mutations and genetic heterogeneity at the CDKN1B locus in small intestinal neuroendocrine tumors. Annals of Surgical Oncology 22 (Supplement 3) S1428-S1435. (https://doi.org/10.1245/s10434-014-4351-9)

Drilon A, Laetsch TW, Kummar S, Dubois SG, Lassen UN, Demetri GD, Nathenson M, Doebele RC, Farago AF, Pappo AS, et al. 2018 Efficacy of larotrectinib in TRK fusion-positive cancers in adults and children. New England Journal of Medicine 378 731-739. (https://doi. org/10.1056/NEJMoa1714448)

Elisei R, Schlumberger MJ, Müller SP, Schöffski P, Brose MS, Shah MH, Licitra L, Jarzab B, Medvedev V, Kreissl MC, et al. 2013 Cabozantinib in progressive medullary thyroid cancer. Journal of Clinical Oncology 31 3639-3646. (https://doi.org/10.1200/JCO.2012.48.4659)

Ellis L, Shale MJ \& Coleman MP 2010 Carcinoid tumors of the gastrointestinal tract: trends in incidence in England since 1971. American Journal of Gastroenterology 105 2563-2569. (https://doi. org/10.1038/ajg.2010.341)

Fernández-Cuesta L, Peifer M, Lu X, Sun R, Ozretić L, Seidal D, Zander T, Leenders F, George J, Müller C, et al. 2014 Frequent mutations in chromatin-remodelling genes in pulmonary carcinoids. Nature Communications 5 3518. (https://doi.org/10.1038/ncomms4518)

Floridia G, Grilli G, Salvatore M, Pesucci C, Moore PS, Scarpa A \& Taruscio D 2005 Chromosomal alterations detected by comparative genomic hybridization in nonfunctioning endocrine pancreatic tumours. Cancer Genetics and Cytogenetics 156 23-30. (https://doi. org/10.1016/j.cancergencyto.2004.04.015)

Fraenkel M, Faggiano A \& Valk GD 2015 Epidemiology of neuroendocrine tumors. Frontiers of Hormone Research 44 1-23. (https://doi.org/10.1159/000381970)

Francis JM, Kiezun A, Ramos AH, Serra S, Pedamallu CS, Qian ZR, Banck MS, Kanwar R, Kulkarni AA, Karpathakis A, et al. 2013 Somatic mutation of CDKN1B in small intestine neuroendocrine tumors. Nature Genetics 45 1483-1486. (https://doi.org/10.1038/ ng.2821)

Frilling A \& Clift AK 2015 Therapeutic strategies for neuroendocrine liver metastases. Cancer 121 1172-1186. (https://doi.org/10.1002/ cncr.28760)

Garcia-Carbonero R, Sorbye H, Baudin E, Raymond E, Wiedenmann B, Niederle B, Sedlackova E, Toumpanakis C, Anlauf M, Cwikla JB, et al. 2016 Enets consensus guidelines for high-grade gastroenteropancreatic neuroendocrine tumors and neuroendocrine carcinomas. Neuroendocrinology 103 186-194. (https://doi. org/10.1159/000443172)

Gatenby RA, Zhang J \& Brown JS 2019 First strike-second strike strategies in metastatic cancer: lessons from the evolutionary dynamics of extinction. Cancer Research 79 3174-3177. (https://doi. org/10.1158/0008-5472.CAN-19-0807)

George J, Lim JS, Jang SJ, Cun Y, Ozretić L, Kong G, Leenders F, Lu X, Fernández-Cuesta L, Bosco G, et al. 2015 Comprehensive genomic profiles of small cell lung cancer. Nature $\mathbf{5 2 4} 47-53$. (https://doi. org/10.1038/nature14664)

Hänninen UA, Katainen R, Tanskanen T, Plaketti RM, Laine R, Hamberg J, Ristimäki A, Pukkala E, Taipale M, Mecklin JP, et al. 2018 Exome-wide somatic mutation characterization of small bowel adenocarcinoma. PLoS Genetics 14 e1007200. (https://doi. org/10.1371/journal.pgen.1007200)

Harrison PT \& Huang PH 2018 Exploiting vulnerabilities in cancer signalling networks to combat targeted therapy resistance. Essays in Biochemistry 62 583-593. (https://doi.org/10.1042/EBC20180016)

Hauso O, Gustafsson BI, Kidd M, Waldum HL, Drozdov I, Chan AKC \& Modlin IM 2008 Neuroendocrine tumor epidemiology: contrasting Norway and North America. Cancer 113 2655-2664. (https://doi. org/10.1002/cncr.23883)

Janes MR, Zhang J, Li LS, Hansen R, Peters U, Guo X, Chen Y, Babbar A, Firdaus SJ, Darjania L, et al. 2018 Targeting KRAS mutant cancers https://erc.bioscientifica.com https://doi.org/10.1530/ERC-20-0074 (c) 2020 Society for Endocrinology Published by Bioscientifica Ltd. Printed in Great Britain 
with a covalent G12C-specific inhibitor. Cell 172 578.e17-589.e17. (https://doi.org/10.1016/j.cell.2018.01.006)

Jia TY, Xiong JF, Li XY, Yu W, Xu ZY, Cai XW, Ma JC, Ren YC, Larsson R, Zhang J, et al. 2019 Identifying EGFR mutations in lung adenocarcinoma by noninvasive imaging using radiomics features and random forest modeling. European Radiology 29 4742-4750. (https://doi.org/10.1007/s00330-019-06024-y)

Jiao Y, Shi C, Edil BH, de Wilde RF, Klimstra DS, Maitra A, Schulick RD, Tang LH, Wolfgang CL, Choti MA, et al. 2011 DAXX/ATRX, MEN1, and mTOR pathway genes are frequently altered in pancreatic neuroendocrine tumors. Science 331 1199-1203. (https://doi. org/10.1126/science.1200609)

Jonkers YM, Claessen SM, Perren A, Schmid S, Komminoth P, Verhofstad AA, Hofland LJ, de Krijger RR, Slootweg PJ, Ramaekers FC, et al. 2005 Chromosomal instability predicts metatstic disease in patients with insulinomas. Endocrine-Related Cancer 12 435-447. (https://doi.org/10.1677/erc.1.00960)

Karpathakis A, Dibra H, Pipinikas C, Feber A, Morris T, Francis J, Oukrif D, Mandair D, Pericleous M, Mohmaduvesh M, et al. 2016 Prognostic impact of novel molecular subtypes of small intestinal neuroendocrine tumor. Clinical Cancer Research 22 250-258. (https:// doi.org/10.1158/1078-0432.CCR-15-0373)

Karpathakis A, Dibra H, Pipinikas C, Feber A, Morris T, Francis J, Oukrif D, Mandair D, Pericleous M, Mohmaduvesh M, et al. 2017 Progressive epigenetic dysregulation in neuroendocrine tumour liver metastases. Endocrine-Related Cancer 24 L21-L25. (https://doi. org/10.1530/ERC-16-0419)

Khan MS, Kirkwood AA, Tsigani T, Lowe H, Goldstein R, Hartley JA, Caplin ME \& Meyer T 2016 Early changes in circulating tumor cells are associated with response and survival following treatment of metastatic neuroendocrine neoplasms. Clinical Cancer Research 22 79-85. (https://doi.org/10.1158/1078-0432.CCR-15-1008)

Kim DH, Nagano Y, Choi IS, White JA, Yao JC \& Rashid A 2008 Allelic alterations in well-differentiated neuroendocrine tumors (carcinoid tumors) identified by genome-wide single nucleotide polymorphism analysis and comparison with pancreatic endocrine tumors. Genes, Chromosomes and Cancer 47 84-92. (https://doi.org/10.1002/ gcc.20510)

Kim ST, Ha SY, Lee S, Ahn S, Lee J, Park SH, Park JO, Lim HY, Kang WK, Kim KM, et al. 2016 The impact of PD-L1 expression in patients with metastatic GEP-NETs. Journal of Cancer 7 484-489. (https://doi. org $/ 10.7150 /$ jca.13711)

Kinross JM, Drymousis P, Jiménez B \& Frilling A 2013a Metabonomic profiling: a novel approach in neuroendocrine neoplasias. Surgery 154 1185-1192; discussion 1192-1193. (https://doi.org/10.1016/j. surg.2013.06.018)

Kinross JM, Drymousis P, Jiménez B \& Frilling A 2013b Metabonomic profiling: a novel approach in neuroendocrine neoplasias. Surgery 154 1185-1192; discussion 1192-1193. (https://doi.org/10.1016/j. surg.2013.06.018)

Komorowski M, Celi LA, Badawi O, Gordon AC \& Faisal AA 2018 The artificial intelligence clinician learns optimal treatment strategies for sepsis in intensive care. Nature Medicine 24 1716-1720. (https://doi. org/10.1038/s41591-018-0213-5)

Kulke MH, Freed E, Chiang DY, Philips J, Zahrieh D, Glickman JN \& Shivdasani RA 2008 High-resolution analysis of genetic alterations in small bowel carcinoid tumors reveals areas of recurrent amplification and loss. Genes, Chromosomes and Cancer 47 591-603. (https://doi. org/10.1002/gcc.20561)

Lefebvre C, Rajbhandari P, Alvarez MJ, Bandaru P, Lim WK, Sato M, Wang K, Sumazin P, Kustagi M, Bisikirska BC, et al. 2010 A human $\mathrm{B}$-cell interactome identifies MYB and FOXM1 as master regulators of proliferation in germinal centers. Molecular Systems Biology 6377. (https://doi.org/10.1038/msb.2010.31)

Leja J, Yu D, Nilsson B, Gedda L, Zieba A, Hakkarainen T, Åkerström G, Öberg K, Giandomenico V \& Essand M 2011 Oncolytic adenovirus modified with somatostatin motifs for selective infection of neuroendocrine tumor cells. Gene Therapy 18 1052-1062. (https:// doi.org/10.1038/gt.2011.54)

Lemelin A, Barritault M, Hervieu V, Payen L, Péron J, Couvelard A, Cros J, Scoazec JY, Bin S, Villeneuve L, et al. 2019 MGMT-NET investigators. Digestive and Liver Disease 51 595-599. (https://doi. org/10.1016/j.dld.2019.02.001)

Luo Y, Chen X, Chen J, Song C, Shen J, Xiao H, Chen M, Li ZP, Huang B \& Feng ST 2020 Preoperative prediction of pancreatic neuroendocrine neoplasms grading based on enhanced computed tomography imaging: validation of deep learning with a convolutional neural network. Neuroendocrinology 110 338-350. (https://doi.org/10.1159/000503291)

Macconaill LE, Garcia E, Shivdasani P, Ducar M, Adusumilli R, Breneiser M, Byrne M, Chung L, Conneely J, Crosby L, et al. 2014 Prospective enterprise-level molecular genotyping of a cohort of cancer patients. Journal of Molecular Diagnostics 16 660-672. (https:// doi.org/10.1016/j.jmoldx.2014.06.004)

Machens A, Niccoli-Sire P, Hoegel J, Frank-Raue K, Van Vroonhoven TJ, Roeher HD, Wahl RA, Lamesch P, Raue F, Conte-Devolx B, et al. 2003 Early malignant progression of hereditary medullary thyroid cancer. New England Journal of Medicine 349 1517-1525. (https://doi. org/10.1056/NEJMoa012915)

Maciel RMB, Camacho CP, Assumpção LVM, Bufalo NE, Carvalho AL, de Carvalho GA, Castroneves LA, de Castro FM, Ceolin L, Cerutti JM, et al. 2019 Genotype and phenotype landscape of MEN2 in 554 medullary thyroid cancer patients: the BrasMEN study. Endocrine Connections 8 289-298. (https://doi.org/10.1530/EC-180506)

Mafficini A \& Scarpa A 2018 Genomic landscape of pancreatic neuroendocrine tumours: the International Cancer Genome Consortium. Journal of Endocrinology 236 R161-R167. (https://doi. org/10.1530/JOE-17-0560)

Malczewska A, Frampton AE, Mato Prado M, Ameri S, Dabrowska AF, Zagorac S, Clift AK, Kos-Kudła B, Faiz O, Stebbing J, et al. 2019 Circulating microRNAs in small-bowel neuroendocrine tumors: a potential tool for diagnosis and assessment of effectiveness of surgical resection. Annals of Surgery [epub]. (https://doi.org/10.1097/ SLA.0000000000003502)

Marini F, Giusti F, Fossi C, Cioppi F, Cianferotti L, Masi L, Boaretto F, Zovato S, Cetani F, Colao A, et al. 2018 Multiple endocrine neoplasia type 1: analysis of germline MEN1 mutations in the Italian multicenter MEN1 patient database. Endocrine 62 215-233. (https:// doi.org/10.1007/s12020-018-1566-8)

Marinoni I, Kurrer AS, Vassella E, Dettmer M, Rudolph T, Banz V, Hunger F, Pasquinelli S, Speel EJ \& Perren A 2014 Loss of DAXX and ATRX are associated with chromosome instability and reduced survival of patients with pancreatic neuroendocrine tumors. Gastroenterology 146 453.e5-460.e5. (https://doi.org/10.1053/j. gastro.2013.10.020)

Miller HC, Drymousis P, Flora R, Goldin R, Spalding D \& Frilling A 2014 Role of Ki-67 proliferation index in the assessment of patients with neuroendocrine neoplasias regarding the stage of disease. World Journal of Surgery 38 1353-1361. (https://doi.org/10.1007/s00268014-2451-0)

Mitrofanova A, Aytes A, Zou M, Shen MM, Abate-Shen C \& Califano A 2015 Predicting drug response in human prostate cancer from preclinical analysis of in vivo mouse models. Cell Reports $\mathbf{1 2}$ 2060-2071. (https://doi.org/10.1016/j.celrep.2015.08.051)

Modlin IM, Kidd M, Malczewska A, Drozdov I, Bodei L, Matar S \& Chung KM 2018 The NETest: the clinical utility of multigene blood analysis in the diagnosis and management of neuroendocrine tumors. Endocrinology and Metabolism Clinics of North America $\mathbf{4 7}$ 485-504. (https://doi.org/10.1016/j.ecl.2018.05.002)

Mok TSK, Wu YL, Kudaba I, Kowalski DM, Cho BC, Turna HZ, Castro G, Srimuninnimit V, Laktionov KK, Bondarenko I, et al. 2019 (c) 2020 Society for Endocrinology Published by Bioscientifica Ltd. Printed in Great Britain 
Pembrolizumab versus chemotherapy for previously untreated, PD-L1-expressing, locally advanced or metastatic non-small-cell lung cancer (KEYNOTE-042): a randomised, open-label, controlled, phase 3 trial. Lancet 393 1819-1830. (https://doi.org/10.1016/S01406736(18)32409-7)

Motzer RJ, Penkov K, Haanen J, Rini B, Albiges L, Campbell MT, Venugopal B, Kollmannsberger C, Negrier S, Uemura M, et al. 2019 Avelumab plus axitinib versus sunitinib for advanced renal-cell carcinoma. New England Journal of Medicine 380 1103-1115. (https:// doi.org/10.1056/NEJMoa1816047)

Moura MM, Cavaco BM \& Leite V 2015 RAS proto-oncogene in medullary thyroid carcinoma. Endocrine-Related Cancer 22 R235-R252. (https://doi.org/10.1530/ERC-15-0070)

Neychev V, Steinberg SM, Cottle-Delisle C, Merkel R, Nilubol N, Yao J, Meltzer P, Pacak K, Marx S \& Kebebew E 2015 Mutation-targeted therapy with sunitinib or everolimus in patients with advanced lowgrade or intermediate-grade neuroendocrine tumours of the gastrointestinal tract and pancreas with or without cytoreductive surgery: protocol for a phase II clinical trial. BMJ Open 5 e008248. (https://doi.org/10.1136/bmjopen-2015-008248)

Oberg K, Krenning E, Sundin A, Bodei L, Kidd M, Tesselaar M, Ambrosini V, Baum RP, Kulke M, Pavel M, et al. 2016 A Delphic consensus assessment: imaging and biomarkers in gastroenteropancreatic neuroendocrine tumor disease management. Endocrine Connections 5 174-187. (https://doi.org/10.1530/EC-16-0043)

Overman MJ, Lonardi S, Wong KYM, Lenz HJ, Gelsomino F, Aglietta M, Morse MA, Van Cutsem E, McDermott R, Hill A, et al. 2018 Durable clinical benefit with nivolumab plus ipilimumab in DNA mismatch repair-deficient/microsatellite instability-high metastatic colorectal cancer. Journal of Clinical Oncology 36 773-779. (https://doi. org/10.1200/JCO.2017.76.9901)

Pagliarini R, Shao W \& Sellers WR 2015 Oncogene addiction: pathways of therapeutic response, resistance, and road maps toward a cure. EMBO Reports 16 280-296. (https://doi.org/10.15252/ embr.201439949)

Pavel M, O'Toole D, Costa F, Capdevila J, Gross D, Kianmanesh R, Krenning E, Knigge U, Salazar R, Pape UF, et al. 2016 Enets consensus guidelines update for the management of distant metastatic disease of intestinal, pancreatic, bronchial neuroendocrine neoplasms (NEN) and NEN of unknown primary site. Neuroendocrinology 103 172-185. (https://doi. org/10.1159/000443167)

Pavel M, Jann H, Prasad V, Drozdov I, Modlin IM \& Kidd M 2017 NET blood transcript analysis defines the crossing of the clinical Rubicon: when stable disease becomes progressive. Neuroendocrinology $\mathbf{1 0 4}$ 170-182. (https://doi.org/10.1159/000446025)

Pea A, Hruban RH \& Wood DH 2016 Genetics of pancreatic neuroendocrine tumors: implications for the clinic. Expert Review of Gastroenterology and Hepatology 9 1407-1419)

Pea A, Yu J, Marchionni L, Noe M, Luchini C, Pulvirenti A, de Wilde RF, Brosens LA, Rezaee N, Javed A, et al. 2020 Genetic analysis of small well-differentiated pancreatic neuroendocrine tumors identifies subgroups with differing risks of liver metastases. Annals of Surgery 271 566-573. (https://doi.org/10.1097/SLA.0000000000003022)

Raue F \& Frank-Raue K 2009 Genotype-phenotype relationship in multiple endocrine neoplasia type 2. Implications for clinical management. Hormones 8 23-28. (https://doi.org/10.14310/ horm.2002.1218)

Raymond E, Dahan L, Raoul JL, Bang YJ, Borbath I, Lombard-Bohas C, Valle J, Metrakos P, Smith D, Vinik A, et al. 2011 Sunitinib malate for the treatment of pancreatic neuroendocrine tumors. New England Journal of Medicine 364 501-513. (https://doi.org/10.1056/ NEJMoa1003825)

Rindi G, Klöppel G, Couvelard A, Komminoth P, Körner M, Lopes JM, McNicol AM, Nilsson O, Perren A, Scarpa A, et al. 2007 TNM staging of midgut and hindgut (neuro) endocrine tumors: a consensus proposal including a grading system. Virchows Archiv 451 757-762. (https://doi.org/10.1007/s00428-007-0452-1)

Romei C, Ciampi R \& Elisei R 2016 A comprehensive overview of the role of the RET proto-oncogene in thyroid carcinoma. Nature Reviews: Endocrinology 12 192-202. (https://doi.org/10.1038/nrendo.2016.11)

Sahnane N, Furlan D, Monti M, Romualdi C, Vanoli A, Vicari E, Solcia E, Capella C, Sessa F \& La Rosa S 2015 Microsatellite unstable gastrointestinal neuroendocrine carcinomas: a new clinicopathologic entity. Endocrine-Related Cancer 22 35-45. (https://doi.org/10.1530/ ERC-14-0410)

Scarpa A, Chang DK, Nones K, Corbo V, Patch AM, Bailey P, Lawlor RT, Johns AL, Miller DK, Mafficini A, et al. 2017 Whole-genome landscape of pancreatic neuroendocrine tumours. Nature 543 65-71. (https://doi.org/10.1038/nature21063)

Schachter J, Ribas A, Long GV, Arance A, Grob JJ, Mortier L, Daud A, Carlino MS, McNeil C, Lotem M, et al. 2017 Pembrolizumab versus ipilimumab for advanced melanoma: final overall survival results of a multicentre, randomised, open-label phase 3 study (KEYNOTE-006). Lancet 390 1853-1862. (https://doi.org/10.1016/ S0140-6736(17)31601-X)

Schlumberger M, Elisei R, Müller S, Schöffski P, Brose M, Shah M, Licitra L, Krajewska J, Kreissl MC, Niederle B, et al. 2017 Overall survival analysis of EXAM, a phase III trial of cabozantinib in patients with radiographically progressive medullary thyroid carcinoma. Annals of Oncology 28 2813-2819. (https://doi. org/10.1093/annonc/mdx479)

Shen X \& Zhao B 2018 Efficacy of PD-1 or PD-L1 inhibitors and PD-L1 expression status in cancer: meta-analysis. BMJ 362 k3529. (https:// doi.org/10.1136/bmj.k3529)

Simbolo M, Vicentini C, Mafficini A, Fassan M, Pedron S, Corbo V, Mastracci L, Rusev B, Pedrazzani C, Landoni L, et al. 2018 Mutational and copy number asset of primary sporadic neuroendocrine tumors of the small intestine. Virchows Archiv $\mathbf{4 7 3}$ 709-717. (https://doi.org/10.1007/s00428-018-2450-x)

Stålberg P, Westin G \& Thirlwell C 2016 Genetics and epigenetics in small intestinal neuroendocrine tumours. Journal of Internal Medicine 280 584-594. (https://doi.org/10.1111/joim.12526)

Staňková K, Brown JS, Dalton WS \& Gatenby RA 2019 Optimizing cancer treatment using game theory: a review. JAMA Oncology $\mathbf{5}$ 96-103. (https://doi.org/10.1001/jamaoncol.2018.3395)

Strosberg J, El-Haddad G, Wolin E, Hendifar A, Yao J, Chasen B, Mittra E, Kunz PL, Kulke MH, Jacene H, et al. 2017 Phase 3 trial of177Lu-dotatate for midgut neuroendocrine tumors. New England Journal of Medicine 376 125-135. (https://doi.org/10.1056/ NEJMoa1607427)

Takahashi D, Kojima M, Suzuki T, Sugimoto M, Kobayashi S, Takahashi S, Konishi M, Gotohda N, Ikeda M, Nakatsura T, et al. 2018 Profiling the tumour immune microenvironment in pancreatic neuroendocrine neoplasms with multispectral imaging indicates distinct subpopulation characteristics concordant with WHO 2017 classification. Scientific Reports 8 13166. (https://doi.org/10.1038/ s41598-018-31383-9)

Verdugo AD, Crona J, Starker L, Stalberg P, Akerstrom G, Westin G, Hellman P \& Bjorklund P 2014 Global DNA methylation patterns through an array-based approach in small intestinal neuroendocrine tumors. Endocrine-Related Cancer 21 L5-L7. (https://doi.org/10.1530/ ERC-13-0481)

Waddell N, Pajic M, Patch AM, Chang DK, Kassahn KS, Bailey P, Johns AL, Miller D, Nones K, Quek K, et al. 2015 Whole genomes redefine the mutational landscape of pancreatic cancer. Nature $\mathbf{5 1 8}$ 495-501. (https://doi.org/10.1038/nature14169)

Wang GG, Yao JC, Worah S, White JA, Luna R, Wu TT, Hamilton SR \& Rashid A 2005 Comparison of genetic alterations in neuroendocrine tumors: frequent loss of chromosome 18 in ileal carcinoid tumors. Modern Pathology 18 1079-1087. (https://doi.org/10.1038/ modpathol.3800389) 
Webb ES, Liu P, Baleeiro R, Lemoine NR, Yuan M \& Wang YH 2018 Immune checkpoint inhibitors in cancer therapy. Journal of Biomedical Research 32 317-326. (https://doi.org/10.7555/ JBR.31.20160168)

Weber MM \& Fottner C 2018 Immune checkpoint inhibitors in the treatment of patients with neuroendocrine neoplasia. Oncology Research and Treatment 41 306-312. (https://doi. org/10.1159/000488996)

Wells SA, Gosnell JE, Gagel RF, Moley J, Pfister D, Sosa JA, Skinner M, Krebs A, Vasselli J \& Schlumberger M 2010 Vandetanib for the treatment of patients with locally advanced or metastatic hereditary medullary thyroid cancer. Journal of Clinical Oncology 28 767-772. (https://doi.org/10.1200/JCO.2009.23.6604)

Wells SA, Robinson BG, Gagel RF, Dralle H, Fagin JA, Santoro M, Baudin E, Elisei R, Jarzab B, Vasselli JR, et al. 2012 Vandetanib in patients with locally advanced or metastatic medullary thyroid cancer: a randomized, double-blind phase III trial. Journal of Clinical Oncology 30 134-141. (https://doi.org/10.1200/JCO.2011.35.5040)

West J, You L, Zhang J, Gatenby RA, Brown JS, Newton PK \& Anderson ARA 2020 Towards multi-drug adaptive therapy. Cancer Research 80 1578-1589. (https://doi.org/10.1158/0008-5472.CAN-192669)

Wild A, Langer P, Celik I, Chaloupka B \& Bartsch DK 2002 Chromosome $22 \mathrm{q}$ in pancreatic endocrine tumours: identification of a homozygous deletion and potential prognostic associations of allelic deletions. European Journal of Endocrinology 147 507-513. (https:// doi.org/10.1530/eje.0.1470507)

Xiong JF, Jia TY, Li XY, Yu W, Xu ZY, Cai XW, Fu L, Zhang J, Qin BJ, Fu XL, et al. 2018 Identifying epidermal growth factor receptor mutation status in patients with lung adenocarcinoma by threedimensional convolutional neural networks. British Journal of Radiology 91 20180334. (https://doi.org/10.1259/bjr.20180334)

Yao JC, Shah MH, Ito T, Bohas CL, Wolin EM, Van Cutsem E, Hobday TJ, Okusaka T, Capdevila J, de Vries EGE, et al. 2011 Everolimus for advanced pancreatic neuroendocrine tumors. New England Journal of Medicine 364 514-523. (https://doi.org/10.1056/ NEJMoa1009290)

Yao JC, Fazio N, Singh S, Buzzoni R, Carnaghi C, Wolin E, Tomasek J, Raderer M, Lahner H, Voi M, et al. 2016 Everolimus for the treatment of advanced, non-functional neuroendocrine tumours of the lung or gastrointestinal tract (RADIANT-4): a randomised, placebo-controlled, phase 3 study. Lancet 387 968-977. (https://doi. org/10.1016/S0140-6736(15)00817-X)

Zhang J, Stevens FGM \& Bradshaw TD 2011 Temozolomide: mechanisms of action, repair and resistance. Current Molecular Pharmacology 5 102-114. (https://doi.org/10.2174/1874467211205010102)

Zhao J, Moch H, Scheidweiler AF, Baer A, Schäffer AA, Speel EJ, Roth J, Heitz PU \& Komminoth P 2001 Genomic imbalances in the progression of endocrine pancreatic tumours. Genes, Chromosomes and Cancer 32 364-372. (https://doi.org/10.1002/gcc.1201)

Received in final form 11 June 2020

Accepted 15 June 2020

Accepted Manuscript published online 16 June 2020 (c) 2020 Society for Endocrinology Published by Bioscientifica Ltd. Printed in Great Britain 